\title{
C-Reactive Protein and Procalcitonin in Case Reports of Drug Reaction with Eosinophilia and Systemic Symptoms (DRESS) Syndrome
}

Hübner, Simona T ; Bertoli, Raffaela ; Rätz Bravo, Alexandra E ; Schaueblin, Martina ; Haschke, Manuel ; Scherer, Kathrin ; Ceschi, Alessandro ; Leuppi-Taegtmeyer, Anne B

\begin{abstract}
BACKGROUND: The spectrum of inflammatory marker response in DRESS (drug reaction with eosinophilia and systemic symptoms) syndrome has not been systematically characterized. METHODS: An epidemiological biomarker study of C-reactive protein (CRP) and procalcitonin (PCT) values in patients with DRESS syndrome reported at 2 regional pharmacovigilance centers in Switzerland or published in the medical literature 2008-2016 was performed. RESULTS: Ninety-four DRESS cases were studied. All cases showed a CRP value $>10 \mathrm{mg} / \mathrm{L}$ (the upper limit of normal). The mean CRP value was $109.2 \pm 79.4 \mathrm{mg} / \mathrm{L}$. CRP values were significantly higher in 22 cases where a cause of inflammation besides DRESS could not be excluded (mean 162.1 vs. $92.9 \mathrm{mg} / \mathrm{L} ; \mathrm{p}=0.003$ ). Receiver operator characteristics curve analysis showed a moderate performance with a CRP cut-off value of $99.4 \mathrm{mg} / \mathrm{L}$ (AUC $0.717)$ to distinguish between patients with and without a possible additional cause of inflammation. The mean and median PCT values were $2.44 \pm 5.94$ and $0.69 \mathrm{ng} / \mathrm{mL}$, respectively $(\mathrm{n}=25$ patients). Patients in whom an additional cause of inflammation besides DRESS could not be excluded showed a median PCT of $1.37 \mathrm{ng} / \mathrm{mL}(\mathrm{n}=9)$ versus $0.67 \mathrm{ng} / \mathrm{mL}(\mathrm{n}=16)$ in patients with DRESS only. PCT values were above the normal cut-off of $0.1 \mathrm{ng} / \mathrm{mL}$, suggestive of bacterial infection in all but 1 case. Furthermore, there was a correlation between PCT values and hepatic enzyme measurements. CONCLUSIONS: Evaluating CRP and PCT values might be of use in helping physicians to distinguish between cases of DRESS syndrome with and without concurrent infection or other causes of inflammation. Further prospective investigation is required to define the use of these inflammatory markers in the management of DRESS.
\end{abstract}

DOI: https://doi.org/10.1159/000487670

Posted at the Zurich Open Repository and Archive, University of Zurich

ZORA URL: https://doi.org/10.5167/uzh-151199

Journal Article

Published Version

Originally published at:

Hübner, Simona T; Bertoli, Raffaela; Rätz Bravo, Alexandra E; Schaueblin, Martina; Haschke, Manuel; Scherer, Kathrin; Ceschi, Alessandro; Leuppi-Taegtmeyer, Anne B (2018). C-Reactive Protein and Procalcitonin in Case Reports of Drug Reaction with Eosinophilia and Systemic Symptoms (DRESS) Syndrome. International Archives of Allergy and Immunology, 176(1):44-54.

DOI: https://doi.org/10.1159/000487670 


\title{
C-Reactive Protein and Procalcitonin in Case Reports of Drug Reaction with Eosinophilia and Systemic Symptoms (DRESS) Syndrome
}

\author{
Simona T. Hübner ${ }^{a}$ b Raffaela Bertolic Alexandra E. Rätz Bravo ${ }^{b}$ \\ Martina Schaueblind Manuel Haschke ${ }^{e, f}$ Kathrin Scherer ${ }^{a, g}$ \\ Alessandro Ceschic, h Anne B. Leuppi-Taegtmeyer ${ }^{\mathrm{a}, \mathrm{b}}$ \\ a University of Basel, Basel, Switzerland; ${ }^{b}$ Division of Clinical Pharmacology and Toxicology and Regional \\ Pharmacovigilance Center, University Hospital Basel, Basel, Switzerland; ' Division of Clinical Pharmacology and \\ Toxicology and Regional Pharmacovigilance Center, Institute of Pharmacological Sciences of Southern Switzerland,

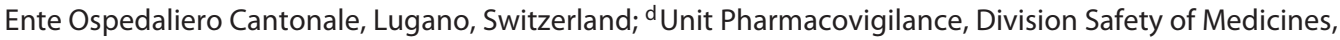 \\ Swissmedic, Swiss Agency for Therapeutic Products, Bern, Switzerland; ${ }^{e}$ Clinical Pharmacology and Toxicology, \\ Department of General Internal Medicine, Inselspital, Bern University Hospital, University of Bern, Bern, Switzerland; \\ ${ }^{f}$ Institute of Pharmacology, University of Bern, Bern, Switzerland; ${ }^{9}$ Allergy Unit, Department of Dermatology, \\ University Hospital Basel, Basel, Switzerland; h Department of Clinical Pharmacology and Toxicology, University \\ Hospital Zurich, Zurich, Switzerland
}

\section{Keywords}

Drug reaction with eosinophilia and systemic symptoms . DRESS syndrome · Inflammatory markers · C-reactive protein · Procalcitonin · Liver enzymes

\footnotetext{
Abstract

Background: The spectrum of inflammatory marker response in DRESS (drug reaction with eosinophilia and systemic symptoms) syndrome has not been systematically characterized. Methods: An epidemiological biomarker study of C-reactive protein (CRP) and procalcitonin (PCT) values in patients with DRESS syndrome reported at 2 regional pharmacovigilance centers in Switzerland or published in the medical literature 2008-2016 was performed. Results: Ninety-four DRESS cases were studied. All cases showed a CRP value $>10 \mathrm{mg} / \mathrm{L}$ (the upper limit of normal). The mean CRP value was $109.2 \pm 79.4 \mathrm{mg} / \mathrm{L}$. CRP values were significantly higher in 22 cases where a cause of inflammation be-
}

sides DRESS could not be excluded (mean 162.1 vs. 92.9 $\mathrm{mg} / \mathrm{L} ; p=0.003)$. Receiver operator characteristics curve analysis showed a moderate performance with a CRP cut-off value of $99.4 \mathrm{mg} / \mathrm{L}$ (AUC 0.717) to distinguish between patients with and without a possible additional cause of inflammation. The mean and median PCT values were $2.44 \pm 5.94$ and $0.69 \mathrm{ng} / \mathrm{mL}$, respectively ( $n=25$ patients). Patients in whom an additional cause of inflammation besides DRESS could not be excluded showed a median PCT of $1.37 \mathrm{ng} / \mathrm{mL}$

Some of our data were obtained from Swissmedic, who reports to the WHO Collaborating Centre for International Drug Monitoring in Uppsala, Sweden. Data from spontaneous reporting are inhomogeneous as a result of different reporting policies, and vulnerable to underreporting and reporting bias. The information in this work comes from different sources and the likelihood of a causal relationship is not the same in all reports. The information does not represent a pharmacovigilance signal or the opinion of Swissmedic or the WHO. Edited by: H. Saito, Tokyo.

\section{KARGER}

(C) 2018 S. Karger AG, Basel

E-Mail karger@karger.com

www.karger.com/iaa
Correspondence to: Dr. Anne. B. Leuppi-Taegtmeyer

Clinical Pharmacology and Toxicology, University Hospital Basel

Schanzenstrasse 55

$\mathrm{CH}-4031$ Basel (Switzerland)

E-Mail anne.leuppi-taegtmeyer@usb.ch 
$(n=9)$ versus $0.67 \mathrm{ng} / \mathrm{mL}(n=16)$ in patients with DRESS only. PCT values were above the normal cut-off of $0.1 \mathrm{ng} / \mathrm{mL}$, suggestive of bacterial infection in all but 1 case. Furthermore, there was a correlation between PCT values and hepatic enzyme measurements. Conclusions: Evaluating CRP and PCT values might be of use in helping physicians to distinguish between cases of DRESS syndrome with and without concurrent infection or other causes of inflammation. Further prospective investigation is required to define the use of these inflammatory markers in the management of DRESS.

(C) 2018 S. Karger AG, Basel

\section{Introduction}

Inflammation occurs in the delayed-type adverse drug reaction called DRESS (drug reaction with eosinophilia and systemic symptoms) syndrome. Typical features of DRESS include fever, lymphadenopathy, skin eruptions, and the involvement of an organ, most commonly the liver [1]. The diagnostic criteria for DRESS are defined by the RegiSCAR score, derived from data collected by the European Registry of Severe Cutaneous Adverse Reactions (SCAR) to Drugs, published by Kardaun et al. [1] The score is based on both clinical and laboratory features; the latter include hematological abnormalities and markers of organ involvement. A particularity of DRESS is a late onset of symptoms, namely $2-8$ weeks after starting the culprit drug. Symptoms persist for at least 2 weeks or more after onset, despite removal of the culprit drug. Early and accurate diagnosis of DRESS remains challenging since it may be confused with other causes of systemic inflammation, including autoimmune diseases and viral, bacterial, or parasitic infections. The interpretation of laboratory markers of inflammation is particularly challenging in cases where, for example, an antibiotic used to treat an infection may have caused DRESS. Approximately $23 \%$ of DRESS cases in the RegiSCAR study were caused by antibiotics [1]. In other cases, physicians may be prompted to initiate antibiotics due to elevated inflammatory markers, when these might not be indicated. Cases of suspected DRESS syndrome therefore often pose diagnostic challenges and therapeutic dilemmas to the treating physicians, particularly with regard to commencing or continuing anti-infective treatment. Moreover, the clinical course of DRESS is worsened if the diagnosis is delayed and the culprit drug not discontinued.

Laboratory markers of inflammation include elevated C-reactive protein (CRP) and leukocyte counts. CRP is an acute-phase protein, which increases up to 1,000-fold in inflammation. It is produced by the liver in response to increased IL-6, and has proinflammatory effects in mediating both the humoral and cellular effector cell pathways of the innate immune system [2]. Normal laboratory values of CRP in the population are up to 10 $\mathrm{mg} / \mathrm{L}$. Values above this are considered to be associated with inflammation. A study of 545 patients found that among 53 patients with CRP $>100 \mathrm{mg} / \mathrm{L}, 83 \%$ had bacterial infections [3]. Another study of 130 patients with CRP $>500 \mathrm{mg} / \mathrm{L}$ found bacterial infection to be the underlying cause in $88 \%$ [4]. However, nonbacterial inflammation may cause an equally high elevation of CRP. A study of 24 patients with DRESS syndrome showed a mean CRP value of $131 \mathrm{mg} / \mathrm{L}(14-467 \mathrm{mg} / \mathrm{L})$ and $>150$ $\mathrm{mg} / \mathrm{L}$ in 8 patients [5]. The study also showed a leukocyte count elevation with a mean value of $18.5 \mathrm{~g} / \mathrm{L}$ in DRESS patients (normal range $4-10 \mathrm{~g} / \mathrm{L}$ ).

A more specific marker of bacterial infection is procalcitonin (PCT). Its value correlates with the severity of the infection. The normal range is $<0.1 \mathrm{ng} / \mathrm{mL}$ [6]. Like CRP, it may increase up to 1,000 -fold, and it is part of a tissue-based host defense mechanism. A cut-off value of $<1 \mathrm{ng} / \mathrm{mL}$ is proposed for distinguishing bacterial infections from a viral infection [7] or autoimmune inflammatory condition [8]. Meta-analyses have shown that PCT has higher accuracy than CRP in distinguishing bacterial from viral infection and other inflammatory conditions such as exacerbation of an underlying autoimmune disease or drug fever [9-11]. However, PCT may be elevated in the absence of a bacterial infection, e.g., after tissue damage due to severe mechanical or surgical trauma, chemical pneumonitis, pancreatitis, burns, or heatstroke. Whether PCT is elevated in DRESS patients is not currently well described due to a paucity of data. Only a few literature cases and studies report PCT values [12-15].

Because the extent of CRP and PCT elevation in patients with DRESS syndrome is currently not accurately known, we conducted a study looking at these parameters in DRESS cases reported at the pharmacovigilance centers in north-western and southern Switzerland and also cases reported in the medical literature.

\section{Material and Methods}

Selection of Cases

A retrospective descriptive analysis was performed. The data were obtained from individual case safety reports (ICSRs) in the databases of the regional pharmacovigilance centers (RPVCs) in 
north-western and southern Switzerland. Both RPVCs report to the Swiss drug authority, Swissmedic, that is part of the drug monitoring system coordinated by the World Health Organization (WHO). All data from the RPVCs are reported in a completely anonymized fashion, so no approval from the ethics committee was needed for this study according to Swiss law.

We searched the database of the 2 regional centers for cases reported in 2008-2016 that contained either the adverse drug reaction term "DRESS" or 2 characteristic DRESS features occurring as joined terms in the title of the ICSR: "hypersensitivity reaction," "hypereosinophilia," "rash," "liver enzyme elevation," "interstitial pneumonitis," "interstitial nephritis," and "myocarditis." No ICSRs were published in the medical literature and all were scrutinized for double-reporting. In order to compare the DRESS data from the RPVCs with published case reports, we searched PubMedMEDLINE for "DRESS," "drug reaction with eosinophilia and systemic symptoms," or "drug-induced hypersensitivity syndrome," and "C-reactive protein," or "procalcitonin" with and without the use of MeSH terms. Case reports were limited to the years 20092016, and to those published in English, French, or German. No conference abstracts were included. Cases for which at least 1 CRP or PCT value was available were included.

We evaluated each RPVC DRESS case by applying the RegiSCAR scoring system [1]. Cases were classified as a "definite case" ( $\geq 6$ points), a "probable case" (4-5 points), a "possible case" (2-3 points), or "no case" ( $0-1$ point). Cases with scores $<2$ points were excluded from the analysis (Fig. 1).

The RegiSCAR scoring system includes clinical and hematological characteristics, namely, fever $>38.5^{\circ}$, lymphadenopathy, eosinophilia $>700 / \mu \mathrm{L}$, the presence of atypical lymphocytes, rash on $>50 \%$ of the body surface, exanthema suggestive of DRESS including maculopapular exanthema, palpable purpura, facial edema or desquamation, skin biopsy compatible with DRESS, the involvement of an organ (liver, kidney, lung, or heart), a time to resolution of $>15$ days and the exclusion of $>3$ differential diagnoses among the following: infection with hepatitis A, B, or C, Mycoplasma or Chlamydia pneumoniae and other positive serology according to polymerase chain reaction, blood cultures, or results for antinuclear antibodies [1].

Literature cases were evaluated either according to their published scores (the RegiSCAR score or the Japanese Consensus Group for Drug-Induced Hypersensitivity Syndrome [16]), if available, or according to the RegiSCAR score determined using the reported clinical details. Missing values were awarded the same number of points as values not fulfilling the diagnostic criteria in accordance with the instructions for completing the RegiSCAR DRESS validation score [1]. The presence of missing data points could thus not lead to the overrating of cases, and is even likely to have caused underrating in some instances.

For each case, we determined if another underlying condition such as infection, autoimmune disease, or malignancy (all known to be associated with raised inflammatory markers [17-19]) could have caused the CRP and PCT elevations. Cases where DRESS was the only cause of inflammation were assigned to group A and the remaining cases to group $\mathrm{B}$, for ease of comparison (Fig. 1).

\section{Data Collection}

Demographic features (sex and age), laboratory values (peak available values for CRP, PCT, and leukocyte and eosinophil counts), clinical features (the presence of fever, lymphadenopa-

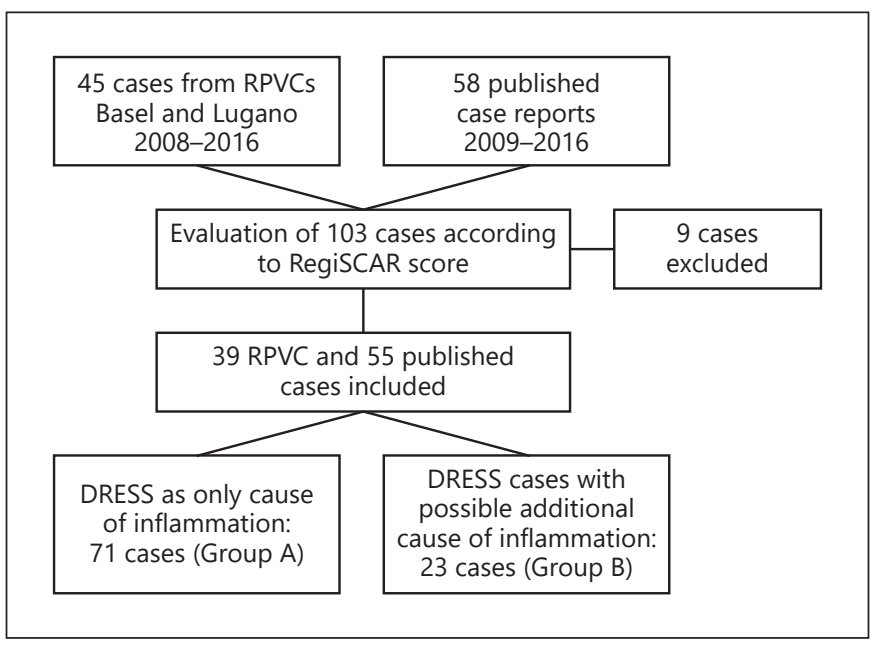

Fig. 1. Inclusion of RPVC and literature cases.

thy, organ involvement, skin manifestations, and outcome), and suspected drugs along with their corresponding indications were extracted from the ICSRs and the literature case reports, and listed in an electronic spreadsheet (MS Excel 2010). Furthermore, the association between the suspected drug and DRESS as given in the RPVC reports was recorded. In the ICSRs, the suspected drugs were assessed by the pharmacovigilance experts at the RPVCs as having a "certain," "probable," "possible," or "unlikely" causal relationship with the development of DRESS according to the WHO/Uppsala Monitoring Centre (WHO-UMC) system for causality assessment [20]. All cases in which the use of $>1$ possible culprit drug or another possible underlying disease were present were classified as possible, and cases unlikely to be caused by another drug or condition were classified as probable. A certain drug causality was for a drug showing a positive rechallenge (a repeated DRESS event occurring after readministration of the culprit drug). Drugs taken over a period of $>3$ months were labeled as unlikely to have caused DRESS, analogous with the RegiSCAR study [1].

\section{Statistical Analysis}

Statistical analysis was descriptive and was performed using Microsoft Office Excel 2010. Mean and standard deviation, median, and quartile values were calculated as appropriate. $p$ values were calculated by application of the two-tailed Student $t$ test. Non-normally distributed data were log-transformed prior to performing the tests. Receiver operator characteristics (ROC) analysis was performed to determine the optimal cut-off values for CRP and PCT to distinguish cases without and with an additional cause of inflammation (groups $\mathrm{A}$ and $\mathrm{B}$, respectively). These analyses were performed using VassarStats [21]. Pearson correlation coefficients $(r)$ were determined to assess associations between PCT values and other laboratory markers, namely, liver function tests, creatinine values, and eosinophilia. 
Table 1. Case characteristics of all cases together and RPVC and literature cases separately

\begin{tabular}{|c|c|c|c|c|}
\hline & All cases & RPVC cases & Literature cases & $p$ value \\
\hline Total number of cases & 94 & 39 & 55 & \\
\hline Mean age \pm SD (range), years & $53.2 \pm 22.6(6-93)$ & $60 \pm 18(22-93)$ & $48.1 \pm 22.7(6-88)$ & 0.06 \\
\hline \multicolumn{5}{|l|}{ RegiSCAR classification [1] } \\
\hline Definite ${ }^{a}$ & $38(40)$ & $9(23)$ & $29(53)$ & 0.005 \\
\hline Probable $e^{b}$ & $38(40)$ & $18(46)$ & $20(36)$ & \\
\hline Cases with no other cause for inflammation & $71(76)$ & $25(64)$ & $46(84)$ & \\
\hline Cases with possible additional cause for inflammation & $23(24)$ & $14(36)$ & $9(16)$ & 0.04 \\
\hline Total number of culprit drugs & 124 & 63 & 61 & \\
\hline \multicolumn{5}{|l|}{ Causality [20] } \\
\hline Certain & & $1(1)$ & not given & \\
\hline Probable & & $17(27)$ & not given & \\
\hline
\end{tabular}

Values express $n(\%)$, unless otherwise indicated.

${ }^{a}$ Score $\geq 6 ;{ }^{b}$ score $4-5 ;{ }^{c}$ score $2-3$.

\section{Results}

\section{Case Characteristics}

A total of 103 potential DRESS cases were identified. Of these, 94 were included: 39 cases from Swiss RPVCs (24 from north-western and 15 from southern Switzerland) and 55 cases from the literature search $[13,14,22-$ 69] (Fig. 1). Details of the 55 literature cases are given in the online supplementary table (for all online suppl. material, see www.karger.com/doi/10.1159/000487670). A comparison of demographic and clinical features is shown in Table 1. The average age of the RPVC cases was older than that of the literature cases; the latter showed a broader range as 7 pediatric DRESS cases (none of them neonates) were included. In both groups, female sex was predominant. Classification of cases by RegiSCAR score showed a higher percentage of definite cases in the literature reports. Two cases in each group had a fatal outcome. In one-third of all cases, skin histology showing perivascular lymphocytic infiltration or epidermal spongiosis was present. Also in one-third of the cases, $>3$ differential diagnoses with similar clinical skin and organ involvement were tested for and excluded.

In all cases together, 57 different culprit drugs were implicated (Table 2). A third of these were antibacterial drugs, followed by antiepileptic drugs (23\% of all cases), sulfonamides (15\%), and allopurinol (11\%). Among the RPVC cases, only 1 case showed a positive rechallenge and was classified as certain, and 17 cases showed probable causality.

\section{CRP, PCT, Leukocyte, and Eosinophil Values}

Values of CRP, PCT, and eosinophil count with corresponding leukocyte count are shown in Table 3. The distribution of CRP and PCT values is illustrated in Figure 2. CRP was measured in $99 \%$ of cases and PCT in $27 \%$ of cases. Leukocyte and eosinophil counts were measured in $>80 \%$ of cases.

\section{Cases Where an Additional Cause of Inflammation Could Not Be Excluded}

We evaluated whether an additional underlying condition could have been responsible for the clinical and laboratory inflammation features. Twenty-five of 39 RPVC cases had DRESS syndrome as the only cause of inflammation (group A) while the remaining 14 cases were evaluated as having a possible additional cause for the elevation in inflammatory markers (group B). In 12 of these 14 cases, an active bacterial infection occurred simultaneously with the DRESS syndrome. These were pneumonia (2 cases), cerebral abscess (2 cases), other abscess ( 2 cases), septic arthritis ( 2 cases), other bacterial infections ( 2 cases), and sepsis (2 cases). Two DRESS cases occurred in patients with hematological malignancies. In the 55 literature reports, only 9 question another possible additional reason for an inflammatory response: pneumonia (1 case), septic arthritis (2 cases), osteomyeli- 
Table 2. Implicated drugs

\begin{tabular}{lc}
\hline Cases with >1 possible culprit drug & $17 / 94(18 \%)$ \\
Indication for culprit drug & \\
Arthritis/colitis/vasculitis & 16 \\
Gout prophylaxis & 12 \\
Epilepsy, migraine, trigeminal neuralgia & 24 \\
Antibacterial use, sepsis excluded & 9 \\
Bacterial infection, sepsis not excluded & 20 \\
Other ${ }^{1}$ & 13 \\
\hline Total number of culprit drugs & $124(100 \%)$ \\
Antibacterials, total & $39(31 \%)$ \\
Amoxicillin & 2 \\
Azithromycin & 1 \\
Benzylpenicillin & 1 \\
Cefazolin & 1 \\
Ceftriaxone & 2 \\
Cefuroxime [22] & 1 \\
Ciprofloxacin & 2 \\
Clindamycin & 1 \\
Daptomycin & 1 \\
Ertapenem & 13 \\
Ethambutol [23, 24] & 1 \\
Imipenem & 1 \\
Isonazid & 1 \\
Levofloxacin & 1 \\
Metronidazole & 1 \\
Minocycline [25] & 1 \\
Piperacillin/tazobactam & 1 \\
Pyrazinamide & 1 \\
Rifampicin [26] & 1 \\
Teicoplanin & 1 \\
Vancomycin [26-32] & 1 \\
Sulfamides, total & 1 \\
Dapsone [33] & 1 \\
Salazosulphapyridine [34] & 1 \\
Sulfamethaxole/trimetoprim [35] & 1 \\
Sulfasalazine [36-44, 69] & 1 \\
& \\
& 1 \\
&
\end{tabular}

tis ( 3 cases), sepsis ( 2 cases), and a first episode of Crohn's disease ( 1 case). In both groups with other possible causes for inflammation, definite, probable, and possible DRESS cases were evenly distributed.

Table 4 shows the comparison between all mean and median values of CRP, PCT, leukocyte count, and eosinophil count of cases with inflammation related to DRESS only (group A), and cases where additional causes for inflammation were possible (group B). Mean CRP values are significantly higher in group $B$ than in group A. ROC analysis gave an area under the curve (AUC) of 0.717 for a cut-off CRP value of $99.4 \mathrm{mg} / \mathrm{L}$ to distinguish between patients without and with an additional cause of

Inflammatory Markers in DRESS

Syndrome

\begin{tabular}{|c|c|}
\hline \\
\hline & Antiepileptics, total \\
\hline Carbamazepine $[13,14,45-51,58]$ & 11 \\
\hline Diphenylhydantoin [52] & 1 \\
\hline Lacosamide & 1 \\
\hline Lamotrigine $[53,54]$ & 5 \\
\hline Levetiracetam $[12,55]$ & 4 \\
\hline Phenobarbital [56] & 1 \\
\hline Phenytoin [57] & 3 \\
\hline Topiramate & 1 \\
\hline Valproate [58] & 2 \\
\hline Others, total & $38(31 \%)$ \\
\hline \multicolumn{2}{|l|}{ Antivirals } \\
\hline Nevirapine & 2 \\
\hline Lamivudine & 1 \\
\hline Raltegravir [59] & 1 \\
\hline \multicolumn{2}{|l|}{ Antimycotics } \\
\hline Itraconazole & 1 \\
\hline L-amphotericin B [60] & 1 \\
\hline Allopurinol [61-64] & 14 \\
\hline \multicolumn{2}{|l|}{ NSAIDs (and related drugs) } \\
\hline Ibuprofen & 1 \\
\hline Paracetamol & 1 \\
\hline Metamizole & 1 \\
\hline \multicolumn{2}{|l|}{ Neuroleptic } \\
\hline Clozapine & 1 \\
\hline Haloperidol & 2 \\
\hline Quetiapine & 1 \\
\hline \multicolumn{2}{|l|}{ Diuretic } \\
\hline Furosemide & 1 \\
\hline \multicolumn{2}{|l|}{ Heparin } \\
\hline Enoxaparin [65] & 1 \\
\hline Dalteparin & 1 \\
\hline \multicolumn{2}{|l|}{ Small-molecule inhibitors } \\
\hline Sorafenib [66] & 1 \\
\hline \multicolumn{2}{|l|}{ Proton-pump inhibitors } \\
\hline Omeprazole [67] & 1 \\
\hline Pantoprazole & 2 \\
\hline Levothyroxine & 1 \\
\hline Strontium ranelate [68] & 1 \\
\hline Tamsulosin & 1 \\
\hline Tribulus terrestris & 1 \\
\hline
\end{tabular}

${ }^{1}$ Fungal infection, HIV, tumor, thrombus prophylaxis, ulcer prophylaxis, and psychosis.

inflammation. Median PCT values were 0.67 and 1.37 $\mathrm{ng} / \mathrm{mL}$ in groups $\mathrm{A}$ and $\mathrm{B}$, respectively. A single outlier in group $\mathrm{A}(30.17 \mathrm{ng} / \mathrm{mL})$ was included in all calculations but is not displayed (Fig. 3), in order to optimize the graphical display. However, the difference was not significant (Table 4). ROC analysis of PCT gave an AUC of 0.677 for a cut-off PCT value of $2.74 \mathrm{ng} / \mathrm{mL}$. Leukocyte 


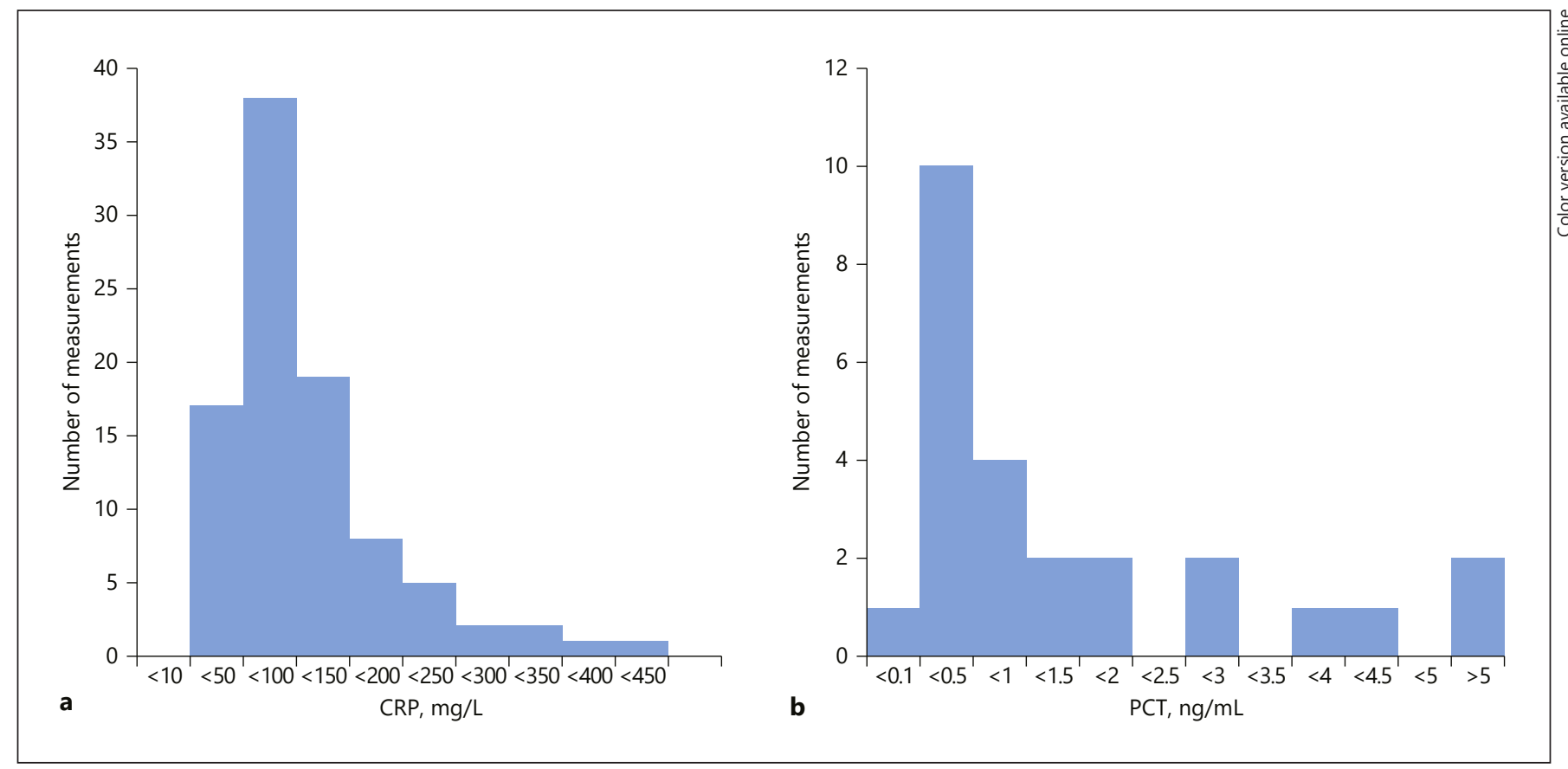

Fig. 2. Distribution of measured CRP (a) and PCT (b) values of all cases. The first column indicates the normal laboratory range, i.e., $\mathrm{CRP}<10 \mathrm{mg} / \mathrm{L}$ and $\mathrm{PCT}<0.1 \mathrm{ng} / \mathrm{mL}$.

Table 3. Mean and median values of CRP, PCT, and leukocyte and eosinophil counts

\begin{tabular}{ll}
\hline & All cases \\
\hline CRP & \\
$\quad$ Number of measurements & $93(99 \%)$ \\
Mean \pm SD (range) & $109.2 \pm 79.4(11.5-420) \mathrm{mg} / \mathrm{L}$ \\
$\quad$ Median (interquartile range) & $90.0(62-138) \mathrm{mg} / \mathrm{L}$ \\
PCT & $25(27 \%)$ \\
Number of measurements & $2.44 \pm 5.93(0.05-30.17) \mathrm{ng} / \mathrm{mL}$ \\
Mean \pm SD (range) & $0.69(0.41-1.80) \mathrm{ng} / \mathrm{mL}$ \\
Median (interquartile range) & $77(82 \%)$ \\
Leukocyte count & $14.49 \pm 11.82(0.3-60) \mathrm{g} / \mathrm{L}$ \\
$\quad$ Number of measurements & $11.9(6.77-16.37) \mathrm{g} / \mathrm{L}$ \\
Mean \pm SD (range) & $79(84 \%)$ \\
Median (interquartile range) & $2.76 \pm 2.96(0-13.96) \mathrm{g} / \mathrm{L}$ \\
Eosinophil count & $1.89(1.16-3.03) \mathrm{g} / \mathrm{L}$ \\
$\quad$ Number of measurements &
\end{tabular}

counts showed similar median values in both groups; eosinophil count, however, showed slightly higher median values in group B.

PCT values were studied in further detail with regard to their association with other laboratory markers. Mod- erate correlations were found between PCT and alanine aminotransferase and aspartate aminotransferase, and a strong correlation wasfound between PCT and $\gamma$-glutamyl transpeptidase (Table 5). 
Fig. 3. Box-plots showing the median, interquartile range, and range of CRP (a) and PCT (b) values of DRESS cases without (group A) and with (group B) a possible additional cause of inflammation. The dashed line indicates the normal laboratory value, i.e., CRP $<10 \mathrm{mg} / \mathrm{L}$ and PCT $<0.1 \mathrm{ng} / \mathrm{mL}$. To optimize graphical display, a single PCT outlier (30.17 $\mathrm{ng} / \mathrm{mL}$ in group A) is not depicted, but its value was included in the calculations.

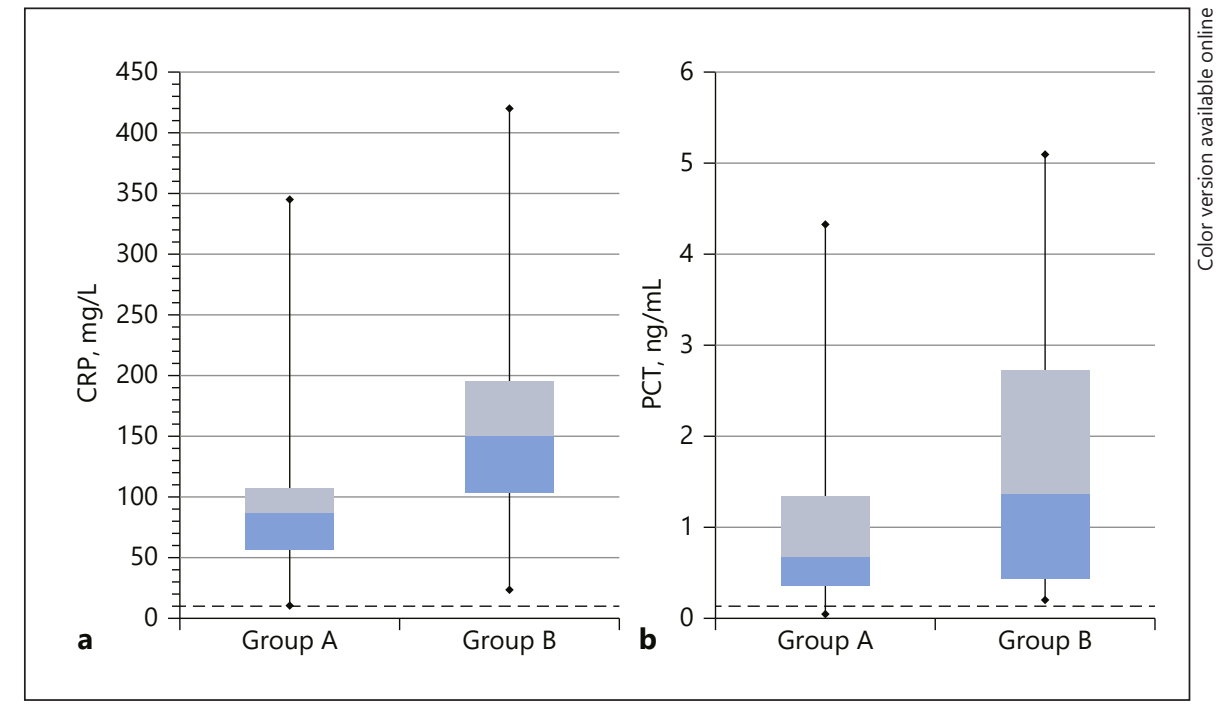

Table 4. Differences in calculated mean and median values of CRP, PCT, and leukocyte and eosinophil counts in 2 groups of patients

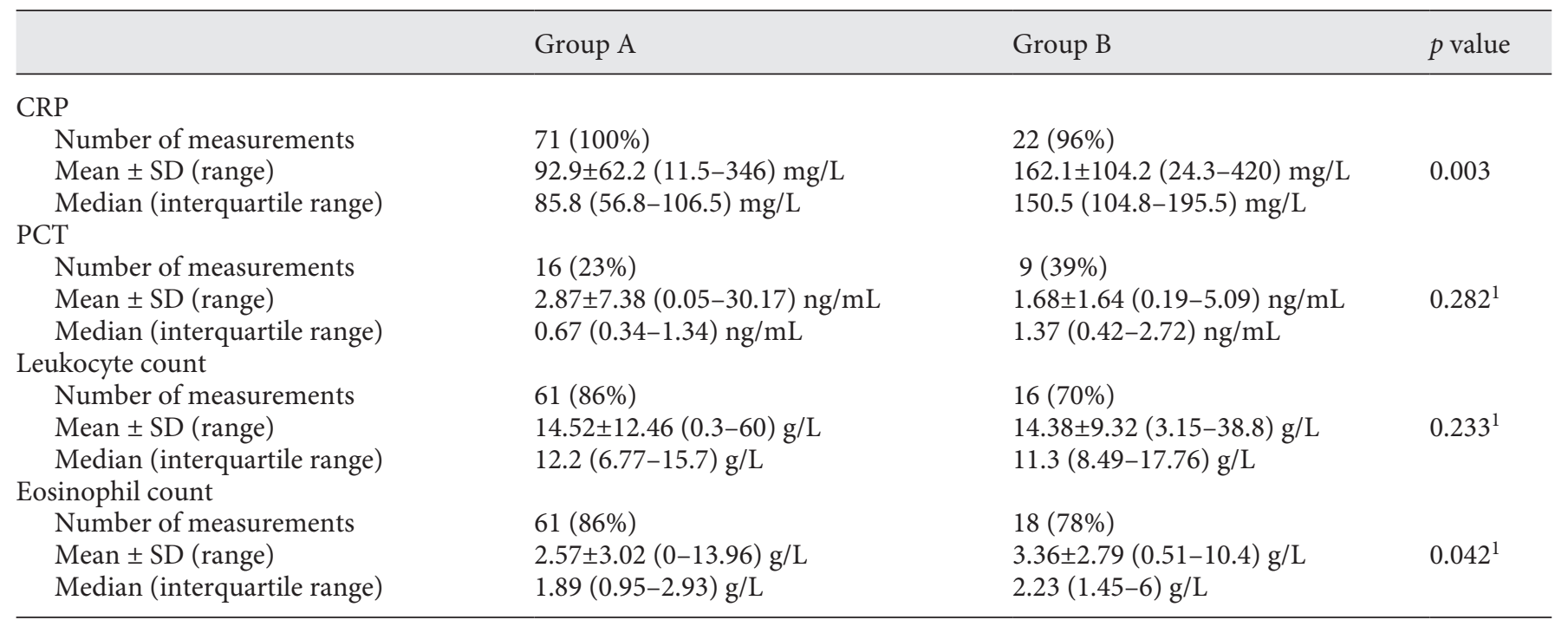

Group A consisted of patients in whom DRESS was the only cause of inflammation and group B consisted of patients in whom there was a possible additional cause.

${ }^{1}$ The Student $t$ test was performed on log-transformed data.

\section{Discussion}

In this observational study of 39 DRESS cases reported to RPVCs in north-western and southern Switzerland, and 55 cases reported in the literature, we found that CRP, PCT, leukocyte, and eosinophil values are elevated, in some cases to levels seen in acute, serious infections.
Furthermore, we observed that CRP and PCT values were higher in cases with a possible additional reason for inflammation.

\section{Case Characteristics}

The demographic and clinical features of the cases reported here are similar to those of a recently published 
Table 5. Correlation coefficients of PCT and other laboratory markers in patients with DRESS syndrome

\begin{tabular}{lll}
\hline Laboratory parameter & $\begin{array}{l}\text { Number of paired } \\
\text { measurements }\end{array}$ & $\begin{array}{l}\text { Correlation } \\
\text { coefficient }\end{array}$ \\
\hline Alanine aminotransferase & 15 & 0.69 \\
Aspartate aminotransferase & 14 & 0.66 \\
Alkaline phosphatase & 10 & 0.17 \\
$\gamma$-Glutamyl transpeptidase & 7 & 0.93 \\
Bilirubin & 4 & 0.13 \\
Creatinine & 13 & 0.10 \\
Absolute eosinophil count & 21 & 0.12 \\
\hline
\end{tabular}

series with 45 cases [70] and a retrospective review of 172 published cases [71], in which $72 \%$ of cases were classified as definite or probable DRESS according to the RegiSCAR score (comparable to the $80 \%$ in this study).

The most frequently reported drugs in this study were sulfasalazine, carbamazepine, and allopurinol. These were also the most frequently reported drugs in the literature review of 2011, followed by other antiepileptic drugs, with antibiotics only being related to a minority of cases [71]. However, in our analysis of RPVC and literature cases, one-third of all suspected drugs were antibiotics and $90 \%$ of cases where an additional cause of inflammation could not be excluded were related to antibiotics. Eight of these were under polymedication, 3 of the patients even received both antibiotic and antiepileptic drugs, for intracranial abscess or meningitis complicated by epilepsy. Such clinical situations are additionally challenging for 2 reasons. Firstly, it is difficult to determine if inflammation markers are elevated due to DRESS or to infection. Secondly, in cases of polymedication, it is not easy to accurately determine and remove the culprit drug causing DRESS.

\section{CRP, PCT, Leukocyte, and Eosinophil Values}

In this study, the mean CRP value was $109.2 \pm 79.4$ $\mathrm{mg} / \mathrm{L}$ in 93 cases. No CRP values were within the normal laboratory range $(<10 \mathrm{mg} / \mathrm{L})$. The diagnostic performance of a CRP cut-off value of $99.4 \mathrm{mg} / \mathrm{L}$ in distinguishing between patients with DRESS only and patients with an additional cause of inflammation was moderate (ROC AUC 0.717) [72]. A study of 24 DRESS patients revealed a mean CRP value of $131 \mathrm{mg} / \mathrm{L}$ [5]. A further study of CRP and PCT profiles in 95 patients with a variety of different drug hypersensitivity reactions included 15 patients with DRESS syndrome [15]; these 15 patients had a mean CRP value of $45.5 \pm 35.4 \mathrm{mg} / \mathrm{L}$. The authors proposed a cut-off value of $66.7 \mathrm{mg} / \mathrm{L}$ in order to distinguish delayed-type drug reactions (95 measurements) from bacterial infection (47 measurements).

Mean PCT value was $>1 \mathrm{ng} / \mathrm{mL}$ in our study. Values $>1 \mathrm{ng} / \mathrm{mL}$ are considered to indicate bacterial infection or sepsis [8-11]. A concurrent bacterial infection was not excluded in one-quarter of the cases in our study. The PCT values of 9 such cases showed a mean value of $1.68 \mathrm{ng} / \mathrm{mL}$ and a median value of $1.37 \mathrm{ng} / \mathrm{mL}$. This was in contrast to the median value of $0.67 \mathrm{ng} / \mathrm{mL}$ among patients who did not have another cause of inflammation. The mean value in this group was, however, higher than among patients with an additional cause of inflammation due to an outlying high value $(30.17 \mathrm{ng} / \mathrm{mL})$. The difference in PCT values was not significant between the 2 groups and the diagnostic performance (using a cut-off of $2.74 \mathrm{ng} / \mathrm{mL}$ ) was low (ROC AUC 0.677), possibly due to the small sample size. In the study by Yoon et al. [15], the mean PCT value was $0.79 \pm 1.54 \mathrm{ng} / \mathrm{mL}$ for 15 patients with DRESS syndrome and a cut-off value of $1.67 \mathrm{ng} / \mathrm{mL}$ distinguished well between patients with delayed-type drug reactions and those with bacterial infections (ROC AUC 0.95). In both our study and Yoon et al. [15], PCT values were observed which were clearly $>1 \mathrm{ng} / \mathrm{mL}$ in the absence of infection. This may be due to the immune-mediated organ injury which is a hallmark of DRESS. Indeed, PCT elevation has been observed in cases of liver injury independent of the presence of bacterial infection. Rule et al. [73] found a median PCT value of $>1.57 \mathrm{ng} / \mathrm{mL}$ in 59 patients with acute liver failure without sepsis. There was also no significant difference in PCT values between the 56 patients with and the 59 patients without bacterial infection. The authors suggested that severe hepatocyte necrosis caused the inflammation that resulted in elevated PCT levels.

Mean leukocyte counts, a further marker of inflammation, were elevated above the normal laboratory range of $10 \mathrm{~g} / \mathrm{L}$, and there was no significant difference between the cases where an additional reason for inflammation besides DRESS could and could not be excluded. This suggests that the leukocyte count is not useful in distinguishing between these 2 types of patients with DRESS syndrome.

Eosinophil counts had mean values $>1.5 \mathrm{~g} / \mathrm{L}$ in both the RPVC and the literature cases. Mean eosinophil counts were significantly higher in cases where an additional inflammatory condition beside DRESS was not excluded. This was unexpected, as bacterial infection, the commonest reason for inflammation in addition to the DRESS syndrome, is not typically associated with eosino- 
philia. We recommend interpreting this finding with caution, however, as the sample size is small and the case-mix heterogeneity is large.

A limited number of paired PCT and other laboratory marker measurements could be assessed for correlation (Table 5). PCT correlated with liver function test measurements (most strongly with $\gamma$-glutamyl transpeptidase), indicating that PCT in DRESS may be an indicator of hepatic tissue damage as found by other investigators [73]. There was no correlation between PCT and eosinophil count (21 paired observations), suggesting that the pathomechanisms of PCT elevation and eosinophilia in DRESS syndrome are independent of each other.

\section{Limitations}

A retrospective study design is associated with more missing data than a prospective study, and, due to the nature of the data sources, investigation was limited to only a single measurement during the course of the condition. There was a clear paucity of PCT measurements, possibly reflecting the general perceived use of this biomarker in clinical practice. However, cases of DRESS are rare, and prospective studies take several years to complete. The rarity of the condition also leads to small sample sizes. An additional limitation is the higher percentage of definite cases among the cases reported in the literature. This may reflect publication bias and the incomplete nature of the information available to the RPVCs, including the results of subsequent allergy tests. Further investigation is required to define the use of CRP and PCT markers in achieving better management of DRESS cases, with and without concurrent infection, or other causes of inflammation.

\section{Conclusions}

CRP and PCT values were found to be elevated in this retrospective observational study of 94 possible, probable, and definite DRESS syndrome cases, even among cases where concurrent infection was excluded. CRP values were significantly higher in patients with possible additional causes for inflammation. Additionally, a PCT value above the normal cut-off (highly suggestive of bacterial infection) may result from DRESS syndrome-associated inflammation alone. Evaluating CRP and PCT values in light of these findings might help physicians to distinguish between cases of DRESS syndrome, with and without concurrent infection, or other causes of inflammation. This may further aid decision-making regarding the best treatment plan for individual cases.

\section{Disclosure Statement}

The authors do not have any conflicts of interest to declare.

\section{References}

1 Kardaun SH, Sekula P, Valeyrie-Allanore L, et al: Drug reaction with eosinophilia and systemic symptoms (DRESS): an original multisystem adverse drug reaction. Results from the prospective RegiSCAR study. Br J Dermatol 2013;169:1071-1080.

2 Gabay C, Kushner I: Acute-phase proteins and other systemic responses to inflammation. N Engl J Med 1999;340:448-454.

3 Morley JJ, Kushner I: Serum C-reactive protein levels in disease. Ann NY Acad Sci 1982; 389:406-418.

4 Vanderschueren S, Deeren D, Knockaert DC, et al: Extremely elevated C-reactive protein. Eur J Intern Med 2006;17:430-433.

5 Ben m'rad M, Leclerc-Mercier S, Blanche P, et al: Drug-induced hypersensitivity syndrome: clinical and biologic disease patterns in $24 \mathrm{pa}-$ tients. Medicine 2009;88:131-140.

6 Muller B, Becker KL: Procalcitonin: how a hormone became a marker and mediator of sepsis. Swiss Med Wkly 2001;131:595-602.
7 Gendrel D, Raymond J, Coste J, et al: Comparison of procalcitonin with C-reactive protein, interleukin 6 and interferon-alpha for differentiation of bacterial vs. viral infections. Pediatr Infect Dis J 1999;18:875-881.

8 Schwenger V, Sis J, Breitbart A, Andrassy K: CRP levels in autoimmune disease can be specified by measurement of procalcitonin. Infection 1998;26:274-276.

9 Simon L, Gauvin F, Amre DK, et al: Serum procalcitonin and C-reactive protein levels as markers of bacterial infection: a systematic review and meta-analysis. Clin Infect Dis 2004; 39:206-217.

10 Mitaka C: Clinical laboratory differentiation of infectious versus non-infectious systemic inflammatory response syndrome. Clin Chim Acta 2005;351:17-29.

11 Limper M, de Kruif MD, Duits AJ, et al: The diagnostic role of procalcitonin and other biomarkers in discriminating infectious from non-infectious fever. J Infect 2010;60:409416.
12 Sfia M, Boeckler P, Lipsker D: High procalcitonin levels in patients with severe drug reactions. Arch Dermatol 2007;143:1591.

13 Cantarin-Extremera V, Castano-De La Mota C, Alvarez-Coca J, et al: Procalcitonin, a high acute phase reactant in antiepileptic hypersentivity syndrome in pediatric age. Eur J Paediatr Neurol 2012;16:200-202.

14 Bonaci-Nikolic B, Jeremic I, Nikolic M, et al: High procalcitonin in a patient with drug hypersensitivity syndrome. Intern Med 2009;48: 1471-1474.

15 Yoon SY, Baek SH, Kim S, et al: Serum procalcitonin as a biomarker differentiating delayed-type drug hypersensitivity from systemic bacterial infection. J Allergy Clin Immunol 2013;132:981-983.

16 Shiohara T, Ushigome Y, Kano Y, Takahashi $\mathrm{R}$ : Crucial role of viral reactivation in the development of severe drug eruptions: a comprehensive review. Clin Rev Allergy Immunol 2015;49:192-202. 
17 Zamani B, Jamali R, Ehteram H: Synovial fluid adenosine deaminase and high-sensitivity C-reactive protein activity in differentiating monoarthritis. Rheumatol Int 2012;32:183188.

18 Chen $\mathrm{CH}$, Chen HA, Liao HT, et al: The clinical usefulness of ESR, CRP, and disease duration in ankylosing spondylitis: the product of these acute-phase reactants and disease duration is associated with patient's poor physical mobility. Rheumatol Int 2015;35:1263-1267.

19 Cao Y, Shi YX, Chen JO, et al: Serum C-reactive protein as an important prognostic variable in patients with diffuse large B cell lymphoma. Tumour Biol 2012;33:1039-1044.

20 http://who-umc.org/Graphics/24734.pdf (accessed 16 January 2017).

21 http://vassarstats.net/index.html (accessed 15 February 2017)

22 Yıldırım Y, Kara AV, Yılmaz Z, et al: Cefuroxime axetil related DRESS (drug reaction with eosinophilia and systemic symptoms) syndrome. Eur J Gen Med 2016;13:161-164.

23 Blair PW, Herrin D, Abaalkhail N, Fiser W: DRESS syndrome presenting after initiation of Mycobacterium avium complex osteomyelitis treatment. BMJ Case Rep 2015, DOI: 10.1136/bcr-2015-210907.

24 Draz N, Datta S, Webster DP, Cropley I: Drug reaction with eosinophilia and systemic symptoms (DRESS) syndrome secondary to antituberculosis drugs and associated with human herpes virus-7 (HHV-7). BMJ Case Rep 2013, DOI: 10.1136/bcr-2013-010348.

25 Kuhn A, Weiler-Normann C, Schramm C, et al: Acute liver failure following minocycline treatment - a case report and review of the literature. Z Gastroenterol 2012;50:771-775.

26 Wendland T, Daubner B, Pichler WJ: Ceftobiprole associated agranulocytosis after drug rash with eosinophilia and systemic symptoms induced by vancomycin and rifampicin. Br J Clin Pharmacol 2011;71:297-300.

27 Guner MD, Tuncbilek S, Akan B, CaliskanKartal A: Two cases with HSS/DRESS syndrome developing after prosthetic joint surgery: does vancomycin-laden bone cement play a role in this syndrome? BMJ Case Rep 2015, DOI: 10.1136/bcr-2014-207028.

28 O'Meara P, Borici-Mazi R, Morton AR, Ellis AK: DRESS with delayed onset acute interstitial nephritis and profound refractory eosinophilia secondary to vancomycin. Allergy Asthma Clin Immunol 2011;7:16.

29 Young S, Ojaimi S, Dunckley H, et al: Vancomycin-associated drug reaction with eosinophilia and systemic symptoms syndrome. Intern Med J 2014;44:694-696.

30 Moriceau F, Prothet J, Blaise BJ, et al: DRESS syndrome in the ICU: when a patient is treated with multiple drugs. Case Rep Crit Care 2016;2016:9453286.

31 Miyazu D, Kodama N, Yamashita D, et al: DRESS syndrome caused by cross-reactivity between vancomycin and subsequent teicoplanin administration: a case report. Am J Case Rep 2016;17:625-631.
32 Song SM, Cho MS, Oh SH, et al: Liver transplantation in a child with acute liver failure resulting from drug rash with eosinophilia and systemic symptoms syndrome. Korean J Pediatr 2013;56:224-226.

33 Schulkes KJ, Tervaert JW, Rijken F, Haas LE: Dapsone hypersensitivity syndrome not related to G6PD deficiency. BMJ Case Rep 2015, DOI: $10.1136 / \mathrm{bcr}-2015-212742$.

34 Tsutsumi R, Adachi K, Yoshida Y, Yamamoto O: Drug-induced hypersensitivity syndrome in association with varicella. Acta Derm Venereol 2015;95:503-504.

35 Sawata T, Bando M, Kogawara H, et al: Druginduced hypersensitivity syndrome accompanied by pulmonary lesions exhibiting centrilobular nodular shadows. Intern Med 2016; 55:1159-1163.

36 Fathallah N, Slim R, Rached S, et al: Sulfasalazine-induced DRESS and severe agranulocytosis successfully treated by granulocyte colony-stimulating factor. Int J Clin Pharm 2015; 37:563-565.

37 Jeremic I, Vujasinovic-Stupar N, Terzic T, et al: Fatal sulfasalazine-induced eosinophilic myocarditis in a patient with periodic fever syndrome. Med Princ Pract 2015;24:195-197.

38 Parkins G, White B: DRESS syndrome presenting like septic shock. QJM 2013;106:671673.

39 Moling O, Tappeiner L, Piccin A, et al: Treatment of DIHS/DRESS syndrome with combined $\mathrm{N}$-acetylcysteine, prednisone and valganciclovir - a hypothesis. Med Sci Monit 2012;18:CS57-CS62.

40 Osman A, Ibrahim W, Khanjar I, et al: Sudden worsening of DRESS syndrome on tapering steroid dose with dramatic improvement on $\mathrm{N}$-acetylcysteine and steroid dose escalation. J Med Biomed Sci 2013;6:101-105.

41 Cherquaoui H, Samlani Z, Oubaha S, Krati K: Dress syndrome on sulfasalazine for Crohn disease. J Afr Hepat Gastroen 2015;9:141143.

42 Rosenbaum J, Alex G, Roberts H, Orchard D: Drug rash with eosinophilia and systemic symptoms secondary to sulfasalazine. J Paediatr Child Health 2010;46:193-196.

43 Girelli F, Bernardi S, Gardelli L, et al: A new case of DRESS syndrome induced by sulfasalazine and triggered by amoxicillin. Case Rep Rheumatol 2013;2013:409152.

44 Hernandez N, Borrego L, Soler E, Hernandez J: Sulfasalazine-induced linear immunoglobulin A bullous dermatosis with DRESS. Actas Dermosifiliogr 2013;104:343-346.

45 Komatsu-Fujii T, Ohta M, Niihara H, Morita E: Usefulness of rapid measurement of serum thymus and activation-regulated chemokine level in diagnosing drug-induced hypersensitivity syndrome. Allergol Int 2015;64:388389.

46 Thistleton S, Grandidge L, Sharlala H, Adebajo A: A hunt for the source of sepsis. BMJ Case Rep 2014, DOI: 10.1136/bcr-2014204169.
47 Morimoto M, Watanabe Y, Arisaka T, et al: A case of drug-induced hypersensitivity syndrome due to carbamazepine. Bull Tokyo Dent Coll 2011;52:135-142.

48 Eguchi E, Shimazu K, Nishiguchi K, et al: Granulomatous interstitial nephritis associated with atypical drug-induced hypersensitivity syndrome induced by carbamazepine. Clin Exp Nephrol 2012;16:168-172.

49 Matsuda H, Saito K, Takayanagi Y, et al: Pustular-type drug-induced hypersensitivity syndrome/drug reaction with eosinophilia and systemic symptoms due to carbamazepine with systemic muscle involvement. J Dermatol 2013;40:118-122.

50 Hase I, Arakawa H, Sakuma H, et al: Bronchoscopic investigation of atypical drug-induced hypersensitivity syndrome showing viral lung involvement. Intern Med 2016;55:2691-2696.

51 Ono Y, Shimo T, Shirafuji Y, et al: Drug-induced hypersensitivity syndrome caused by carbamazepine used for the treatment of trigeminal neuralgia. Case Rep Dent 2016;2016: 4605231 .

52 Leblebici F, Soyal O, Mutlu NM, et al: Diphenylhydantoin induced DRESS syndrome: a case report. Turk J Anaesthesiol Reanim 2014; 42:46-49.

53 Marriott DJ, Periyasamy P: Anticonvulsant hypersensitivity syndrome secondary to lamotrigine mimicking a septic episode. Ann Acad Med Singapore 2011;40:422-423.

54 Nares EM, Iñiguez AL, Saldaña SG, et al: Pseudomembranous colitis in a patient with lamotrigine-induced drug rash with eosinophilia and systemic symptoms syndrome. Gastroenterology Insights 2016;7:22-25.

55 Gomez-Zorrilla S, Ferraz AV, Pedros C, et al: Levetiracetam-induced drug reaction with eosinophilia and systemic symptoms syndrome. Ann Pharmacother 2012;46:e20.

56 Chaabane A, Ben Fadhel N, Chadli Z, et al Phenobarbital-induced DRESS: a lichenoid picture. Iran J Allergy Asthma Immunol 2014; 13:453-455.

57 Kellett S, Cock C: A case of drug reaction with eosinophilia and systemic symptoms. Case Rep Med 2012;2012:705190.

58 Kocaoglu C, Cilasun C, Solak ES, et al: Successful treatment of antiepileptic drug-induced DRESS syndrome with pulse methylprednisolone. Case Rep Pediatr 2013;2013: 928910.

59 Loulergue P, Mir O: Raltegravir-induced DRESS syndrome. Scand J Infect Dis 2012; 44:802-803.

60 Hagihara M, Yamagishi Y, Hirai J, et al: Druginduced hypersensitivity syndrome by liposomal amphotericin-B: a case report. BMC Res Notes 2015;8:510.

61 Turney R, Skittrall JP, Donovan J, Agranoff D: Drug reaction, eosinophilia and systemic symptoms (DRESS) syndrome secondary to allopurinol with early lymphadenopathy and symptom relapse. BMJ Case Rep 2015, DOI: 10.1136/bcr-2015-211222. 
62 Lim HY, Huang GK, Torresi J, Johnson D: Red herring in returned traveler: drug reaction with eosinophilia and systemic symptom (DRESS) syndrome mimicking sepsis. J Travel Med 2014;21:425-428.

63 Kato M, Kano Y, Sato Y, Shiohara T: Severe agranulocytosis in two patients with drug-induced hypersensitivity syndrome/drug reaction with eosinophilia and systemic symptoms. Acta Derm Venereol 2016;96:842-843.

64 Laurisch S, Jaedtke M, Demir R, et al: Allopurinol-induced hypersensitivity syndrome resulting in death. Med Klin 2010;105:262-266.

65 Ronceray S, Dinulescu M, Le Gall F, et al: Enoxaparin-induced DRESS syndrome. Case Rep Dermatol 2012;4:233-237.
66 Kim DK, Lee SW, Nam HS, et al: A case of sorafenib-induced DRESS syndrome in hepatocelluar carcinoma. Korean J Gastroenterol 2016;67:337-340.

67 Bourneau-Martin D, Leclech C, Jamet A, et al: Omeprazole-induced drug reaction with eosinophilia and systemic symptoms (DRESS). Eur J Dermatol 2014;24:413-415.

68 Kinyo A, Belso N, Nagy N, et al: Strontium ranelate-induced DRESS syndrome with persistent autoimmune hepatitis. Acta Derm Venereol 2011;91:205-206.

69 Pirklbauer M, Gruber J: DRESS syndrome following sulfasalazine treatment. Z Rheumatol 2014; $73: 180-183$
70 Skowron F, Bensaid B, Balme B, et al: Drug reaction with eosinophilia and systemic symptoms (DRESS): clinicopathological study of 45 cases. J Eur Acad Dermatol Venereol 2015;29:2199-2205.

71 Cacoub P, Musette P, Descamps V, et al: The DRESS syndrome: a literature review. Am J Med 2011;124:588-597.

72 Fischer JE, Bachmann LM, Jaeschke R: A readers' guide to the interpretation of diagnostic test properties: clinical example of sepsis. Intensive Care Med 2003;29:1043-1051.

73 Rule JA, Hynan LS, Attar N, et al; Acute Liver Failure Study Group: Procalcitonin identifies cell injury, not bacterial infection, in acute liver failure. PLoS One 2015;10:e0138566. 